\title{
O SUPERGRUPO ESPINHAÇO EM MINAS GERAIS: CONSIDERAÇÕES SOBRE SUA ESTRATIGRAFIA E SEU ARRANJO ESTRUTURAL
}

\author{
Luiz Guilherme Knauer
}

\begin{abstract}
This article presents data and interpretations on the Espinhaço Supergroup in Minas Gerais, emphasizing stratigraphic and structural data of the Serra do Espinhaço, where arise sequences from Archean (granites/ gnaisses/migmatites and units of lower metamorphic degree) to Neoproterozoic. Espinhaço Supergroup has it's development in the end of the Paleoproterozoic until the Mesoproterozoic, and in the Meridional Section it's base is represented by the Guinda Group, with quartzites, phylites and metaconglomerates/breccias of fluvial to shallow marine origins, presenting intercalations of metavolcanics and real paleosoils (part of hematitic phylites). Above arise eolian metasediments of the Galho do Miguel Formation and the marine to fluvial metasediments of the Conselheiro Mata Group. At the Setentrional Sector, three big groups, mainly presenting continental characteristics (compatible with the opening of a rift), can be recognized forming this super group in the setentrional sector of the mountain rage: Metavulcanossedimentar Unit, Inferior Metassedimentar Unit and Superior Metassedimentar Unit. The region is structured by a system of inverse faults/ ductile shear zones that cause frequent stratigraphic inversions and that spread marked blocks internally by open folds to closed with West vergence. The analysis of quantity of deformation proves the non-axial character of these mass transportations, and confirms the location of part of the shear zones.
\end{abstract}

\section{INTRODUÇÃO}

A Serra do Espinhaço, com mais de $1200 \mathrm{~km}$ de extensão, atravessa, em direção próxima ao meridiano, os estados da Bahia e de Minas Gerais, onde é separada em dois setores nas proximidades do paralelo $17^{\circ} 00^{\prime} \mathrm{S}$ : Meridional e Setentrional. Com a descoberta dos depósitos diamantíferos no início do século XVIII em terrenos do Setor Meridional, estudos geológicos passaram a se concentrar especialmente na região de Diamantina (ver Figura 1), o que explica a assimetria dos conhecimentos sobre os dois setores até o momento.
A grande quantidade de trabalhos realizados (com sínteses em Renger 1979, Uhlein 1991, Renger \& Knauer 1995 e Knauer, 1999) representou um acúmulo de conhecimentos geológicos que acabaram por caracterizar a região como uma área padrão no ensino da geologia no país, especialmente via Centro de Geologia Eschwege.

A evolução geológica do Supergrupo Espinhaço, principal formador da serra, é ainda controversa. A maioria dos pesquisadores defende um início de desenvolvimento via processos de rifteamento

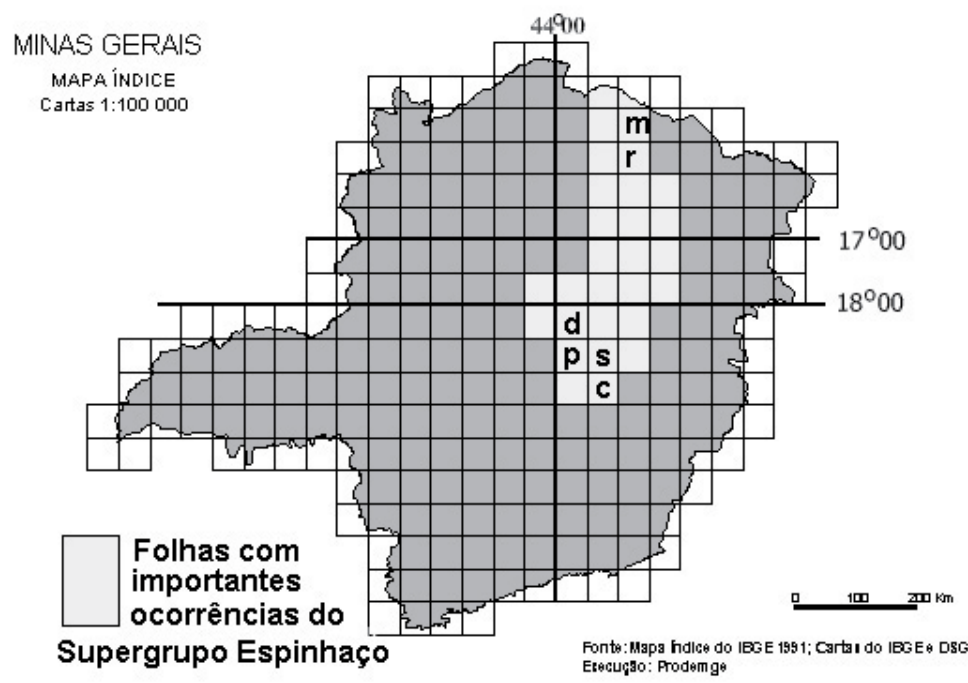

Figura 1-Mapa mostrando a divisão em folhas 1:100.000 de Minas Gerais, com realce (em branco) das principais folhas com ocorrências do Supergrupo Espinhaço. As folhas citadas no texto incluem $m=$ Monte Azul, $r=$ Rio Pardo de Minas, $d=$ Diamantina, $p=$ Presidente Kubitschek,

$$
s=\text { Serro, } c=\text { Conceição do Mato Dentro. }
$$




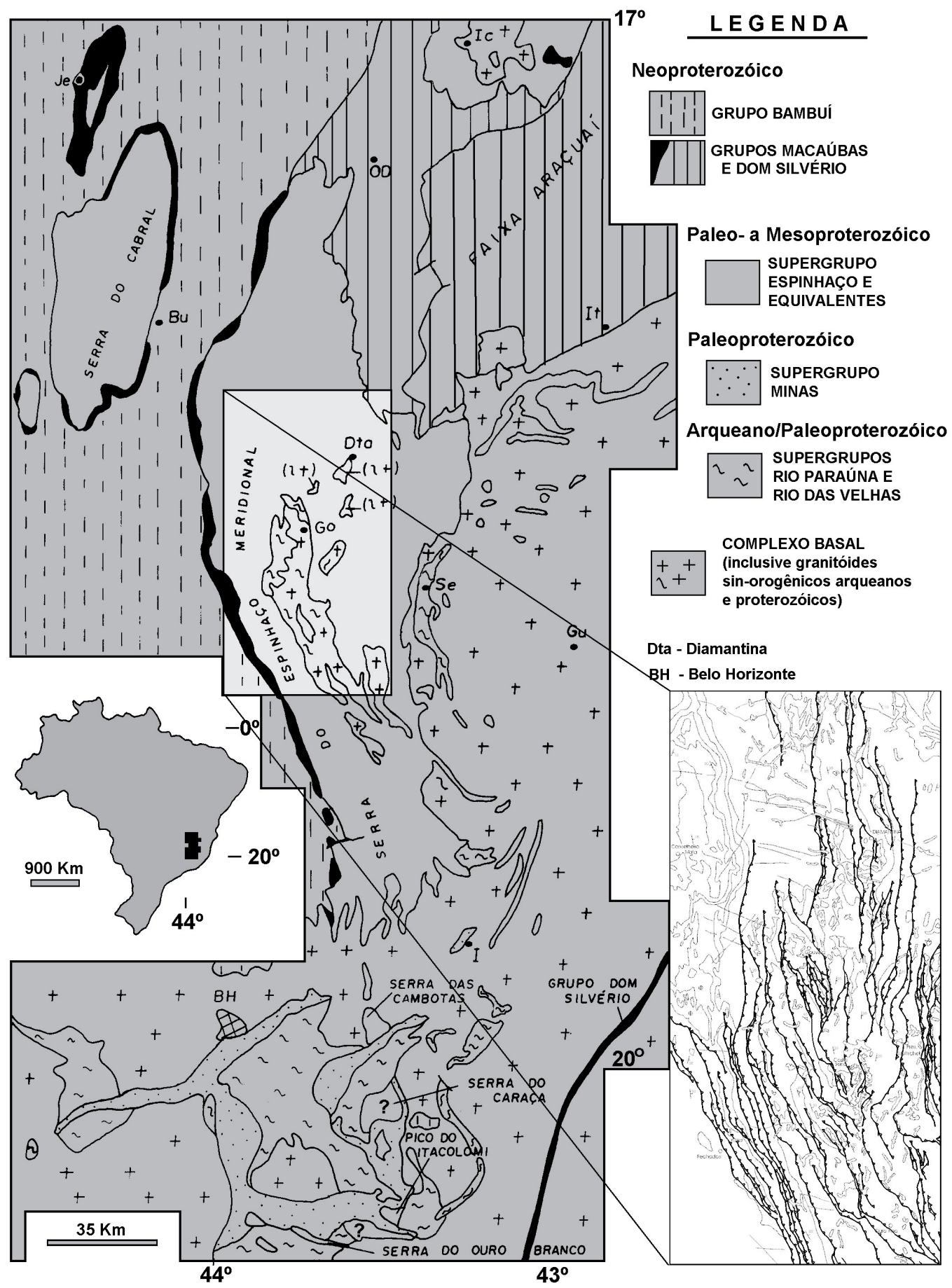

Figura 2 - Mapa do Setor Meridional da Serra do Espinhaço, com realce para as folhas mais detalhadas, como resultado da atuação do C.G. Eschwege. Modificado de Almeida Abreu (1993).

Observar que as falhas de empurrão/zonas de cisalhamento dúctil, omitidas, estão representadas para as folhas Diamantina e Presidente Kubitshek no destaque a direita (Knauer 1999).

no Estateriano (e.g. Brito-Neves et al. 1995), mas a continuidade dos processos durante os tempos mesoproterozóicos ainda não é inteiramente entendida.

\section{TERRENOS PRÉ-ESTATERIANOS DO SETOR MERIDIONAL}

As características estratigráficas do Setor Meridional da Serra do Espinhaço (Figura 2) foram descritas, em sua maior parte, por Pflug (1968) e Schöll e Fogaça (1979), com modificações propostas por Fogaça et al. (1984), Dossin et al. (1984) e Almeida Abreu (1993). Assim, podem ser reconhecidas seqüências rochosas com idades entre o Arqueano e o Neoproterozóico, mas com especial predominância daquelas de idades Paleo- a Mesoproterozóicas relacionadas ao chamado Supergrupo Espinhaço.

No Arqueano, são incluídos complexos granito/gnáissico/migmatíticos englobados sob as 
designações de Complexo de Gouveia (Knauer 1990), na sua região central (com granitos de $2.8 \mathrm{Ga}, \mathrm{U} / \mathrm{Pb}$ em zircões, Machado et al. 1989) e de Complexo Basal, na sua borda leste. Também rochas metamórficas de mais baixo grau são reconhecidas (datação de $2.95 \mathrm{Ga}$ em zircões de metavulcanitos ácidos), representando restos de um possível "greenstone belt" (Grupo Pedro Pereira de Fogaça et al. 1984).

Relacionadas ao Paleoproterozóico (idades em metavulcanitos de $2.05 \mathrm{Ga}, \mathrm{U} / \mathrm{Pb}$ em zircões, Machado et al. 1989), seqüências dominantemente metassedimentares do Grupo Costa Sena (Fogaça et al. 1984) são típicas, sendo reconhecidas as formações Barão do Guaicuí (base) e Bandeirinha. A primeira inclui variados tipos de xistos, muitas vezes com cianita, em alguns afloramentos com lazulita e/ou dumortierita, alem de clorita xistos, quartzitos, BIF's, metaconglomerados e metavulcânicas ácidas.

A Formação Bandeirinha (com até 200 metros) é constituída por quartzitos, normalmente micáceos, com estratificações cruzadas de médio porte, metaconglomerados matriz-suportados e, mais raramente, rochas xistosas, intercaladas especialmente em suas seções mais basais. Almeida-Abreu (1993), Martins-Neto (1993) e Silva (1995) propõem que a Formação Bandeirinha (ou as sequências deposicionais Basal, Olaria e Natureza de Silva, op.cit.) representaria a base do Supergrupo Espinhaço na região de Diamantina. Entre os principais argumentos para estas proposições devem ser citados: a) O contato entre os xistos da Formação Barão do Guaicuí e os quartzitos da Formação Bandeirinha seriam tectônicos; b) As seqüências préEspinhaço seriam todas arqueanas, e não existiriam seqüências continentais com estas características no Arqueano; c) A Formação Bandeirinha incluiria "red beds", os quais teriam seu aparecimento relacionado, na história geológica, ao fim do Paleoproterozóico e ao início do Mesoproterozóico; e d) Os xistos seriam produtos da milonitização de rochas plutônicas, consequentemente impedindo a existência de um caráter gradacional com os quartzitos.

A manutenção do Grupo Costa Sena e de suas formações Barão do Guaicuí e Bandeirinha é aqui proposta, levando em consideração que: a) Ao menos localmente, podem ser observados contatos gradacionais entre o topo da Formação Barão do Guaicuí e a base da Formação Bandeirinha (enquanto aqueles entre esta e as rochas do Supergrupo Espinhaço são discordantes); b) Mesmo em regiões onde os contatos não são observáveis, caracteriza-se um aumento na importância das intercalações quartzíticas no topo da Formação Barão do Guaicuí; c) Pelo menos em algumas regiões (e.g. área de Ouro Fino, no sudeste da Folha Presidente Kubitschek), as intercalações quartzíticas da Formação Barão do Guaicuí têm aspecto petrográfico extremamente similar ao dos típicos quartzitos da Formação Bandeirinha; e d) A Formação Barão do Guaicuí não é arqueana, e sim das porções intermediárias a finais do Paleoproterozóico, conforme demonstrado pela geocronologia $\mathrm{U} / \mathrm{Pb}$ em zircões de metavulcanitos ácidos da região de Ouro Fino.

\section{O SUPERGRUPO ESPINHAÇO NO SETOR MERIDIONAL}

As colunas utilizadas para os estudos do Supergrupo Espinhaço baseiam-se naquelas propostas por Pflug (1968) e Schöll \& Fogaça (1979). As oito formações então definidas e, mesmo que com pequenas modificações, continuam válidas. A reunião destas unidades em entidades maiores foi tentativamente proposta anteriormente (e.g. Dossin et al. 1984; Knauer 1990; Almeida-Abreu \& Renger 2002). No esquema aqui utilizado, são reconhecidos três conjuntos maiores, denominados de Grupo Guinda, Formação Galho do Miguel e Grupo Conselheiro Mata.

O Grupo Guinda (Knauer, 1990) engloba tanto as formações São João da Chapada e Sopa-Brumadinho, como a Formação Itapanhoacanga e a Suíte Metaígnea Conceição do Mato Dentro, estas típicas da borda leste da serra. Muitas vezes, o arranjo relativo entre as unidades, especialmente as ultimas, é pouco claro, especialmente devido ao forte tectonismo da região onde afloram.

Com espessuras de até 200 metros, a Formação São João da Chapada mostra contatos inferiores marcados por discordância erosiva/angular e superiores gradacionais. Schöll \& Fogaça (1979) propuseram três níveis informais, cujas características indicam ambientes continentais. O nível mais basal ("A"), descontínuo, mostra o predomínio de termos quartzíticos sobre metaconglomerados polimíticos e metabrechas quartzíticas.

O "Nível B", com contatos bruscos e espessuras de até 50 metros, é representado por filitos hematíticos (usualmente com predomínio de sericita e hematita) e rochas associadas. Intercalamse xistos verdes (com quem apresentam contatos gradacionais), além de rochas compostas por mais de $70 \%$ de cloritóide e, muito raramente, turmalinitos finos. A caracterização química dos filitos mostra uma surpreendente homogeneidade e valores claramente incompatíveis com uma origem ígnea. Para Knauer \& Schrank (1994), todos os indícios observados levam a admitir uma origem a partir do metamorfismo de rochas ígneas submetidas a processos de alteração que modificaram sua composição inicial. Critérios tais como o caráter estratiforme, contatos superiores bruscos, relativa pequena espessura, destruição das texturas primárias, formação de revestimentos argilosos sobre grãos e crostas de ferro, clastos nos sedimentos de cobertura e foliação paralela ao contato indicam processos de alteração superficial anteriores ao metamorfismo.

Com espessuras que ultrapassam os 150 metros, o Nível C é caracterizado pelo predomínio de quartzitos médios até grosseiros, sobre menores quantidades de filitos e quartzo filitos que gradam lateralmente para quartzitos micáceos finos. Metaconglomerados, na forma 
de lentes métricas, são raros, assim como intercalações de clorita-xistos e/ou de filitos hematíticos.

A Formação Sopa-Brumadinho mostra uma ampla distribuição e um caráter heterogêneo característico, tendo sido objeto de estudos detalhados, especialmente por seu potencial diamantífero. Almeida-Abreu (1993) reconheceu três membros, designados respectivamente de Datas, Caldeirões e Campo Sampaio, este último proposto por Fogaça \& Almeida-Abreu (1982). A estes pode ser adicionada a Unidade Rio Preto (Mourão, 1995).

A porção mais basal (Membro Datas), com espessuras menores que 50 metros, é constituída por filitos e quartzo-filitos que podem gradar lateral e/ou verticalmente para quartzitos finos e micáceos. $\mathrm{O}$ Membro Caldeirões apresenta espessuras oscilando entre os 100 e 200 metros, com predomínio de quartzitos (muitas vezes ferruginosos) sobre os metaconglomerados (usualmente polimíticos e matrizsuportados, localmente diamantíferos), porém com arranjo extremamente heterogêneo do ponto de vista litológico de seção para seção. Termos quartzíticos finos, muito micáceos e algo ferruginosos não são tão raros, assim como intercalações de quartzo filitos acinzentados. Filitos hematíticos são conhecidos, se apresentando como corpos concordantes ou discordantes, da mesma forma como corpos de xistos verdes.

Entre as estruturas sedimentares preservadas desta unidade destacam-se diversos tipos de estratificações cruzadas, de médio a grande porte, incluindo tabulares, tangenciais e acanaladas. Marcas onduladas, tanto simétricas como assimétricas são facilmente reconhecíveis, com variados tamanhos e comprimentos de onda.

O Membro Campo Sampaio inclui, a norte, desde filitos, metassiltitos e quartzitos finos até corpos descontínuos de metabrechas diamantíferas de matriz filítica. Nesta região, mostra um excelente grau de preservação de estruturas sedimentares de pequeno porte, incluindo desde laminações planoparalelas e cruzadas até marcas onduladas, inclusive de interferência. Para sul, a unidade parece tornar-se mais importante (Knauer \& Grossi-Sad 1996a), com predomínio de termos quartzíticos finos.

Com posicionamento similar, as rochas da Unidade Rio Preto afloram em áreas das folhas Presidente Kubitschek e Conceição do Mato Dentro. Ela é caracterizada pela alternância de pacotes decamétricos de quartzitos finos e micáceos, usualmente com conteúdos variáveis de carbonatos e apatita, com sericita xistos também com carbonatos e fosfatos (Mourão 1995).

Com espessuras que devem ultrapassar os 150 metros, e exclusiva da borda leste da serra (Figura 3), a Formação Itapanhoacanga (conforme Knauer \& Grossi-Sad 1996) é caracterizada por variados tipos de quartzitos (gradações locais para quartzo-xistos), com

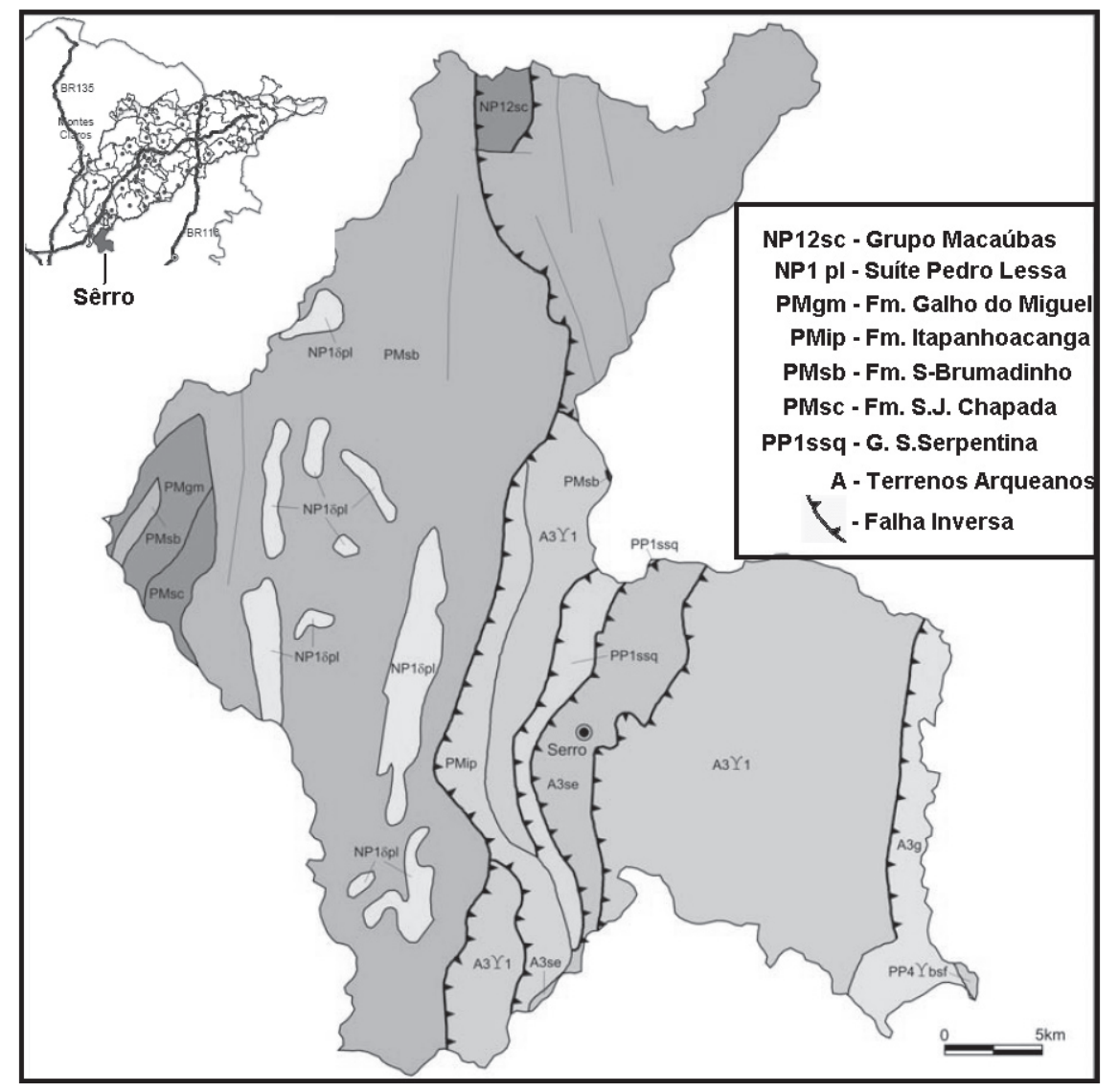

Figura 3 - Mapa esquemático do município de Serro, com distribuição das rochas da Formação Itapanhoacanga. Modificado do "Projeto Cadastro de Abastecimento por Águas Subterrâneas, municipio de Serro" (CPRM 2004). 
intercalações de formações ferríferas bandadas, filitos, filitos hematíticos e metaconglomerados. Seus contatos invariavelmente tectônicos com as outras unidades impedem uma melhor caracterização de suas relações estratigráficas, mas seu caráter litológico, especialmente de algumas de suas intercalações, comprova sua atribuição ao Grupo Guinda.

A Suíte Metaígnea Conceição do Mato Dentro (Knauer, 1990; Knauer \& Grossi-Sad 1996) engloba rochas metavulcânicas/subvulcânicas de filiação ácida. Predominam tipos claros, com "matriz" fina envolvendo fenocristais de quartzo azulado e de feldspato (estes mais raros). Localmente são observadas rochas mais escuras, mas também estas mostram os típicos fenocristais de quartzo. Correspondem aos metariolitos descritos na literatura (e.g. Grossi-Sad \& Mello 1969), com os termos mais escuros representando, segundo Herrgesell (1984), verdadeiros metariodacitos. Datações U/Pb nestas rochas forneceram idades entre 1.70 e $1.72 \mathrm{Ga}$ (Machado et al 1989).

A Formação Galho do Miguel (Tectonossequência Galho do Miguel de Martins-Neto 1998) é caracterizada por quartzitos puros e finos que constituem mais de $90 \%$ da unidade. Os outros 5 ou $10 \%$ estão representados por quartzitos finos micáceos e por finas intercalações de metargilitos acinzentados ou esverdeados. A capacidade de preservação de estruturas nos quartzitos é excepcionalmente boa, incluindo estratificações planoparalelas e cruzadas (acanaladas, tabulares e tangenciais a base, com portes métricos até decamétricos). Marcas onduladas também são comuns, e o conjunto de características indica ambiente dominantemente eólico para sua deposição (Dossin et al. 1987).

As unidades de provável idade mesoproterozóica estão representadas pela Formação Galho do Miguel e pelas seqüências metassedimentares do Grupo Conselheiro Mata (possível bacia interna pós-flexural). Este último é constituído, na base, por quartzitos, filitos e restritos metaconglomerados da Formação Santa Rita, que gradam verticalmente para os quartzitos (finos a médios) da Formação Córrego dos Borges, que pode apresentar intercalações de metabrechas quartzíticas e de metaconglomerados. Mais acima, aparece a Formação Córrego da Bandeira, com base filítica/metassiltítica que grada verticalmente para topo quartzítico fino a médio, localmente feldspático, substituída gradacionalmente pelos quartzitos finos a médios (localmente puros) da Formação Córrego Pereira. No topo, mas nem sempre presente, aparece a Formação Rio Pardo Grande, com metassiltitos e metargilitos substituídos verticalmente por quartzitos finos e muito micáceos. Nestas seções superiores podem aparecer intercalações finas de rochas calcáreas, interpretadas como restos de esteiras algais.

\section{O SUPERGRUPO ESPINHAÇO NO SETOR SETENTRIONAL}

O Supergrupo Espinhaço no Setor Setentrional da serra (Figura 4) pode ser correlacionado, pelos dados existentes, ao chamado Grupo Guinda (na concepção de Knauer 1999), se bem que, para a maior parte da sua área de ocorrência, uma divisão formal ainda não possa ser proposta. Em Itacambira, Karfunkel e Karfunkel (1975) propuseram uma subdivisão em quatro formações, as quais, da base para o topo, são: Itacambiruçu (até 40 metros de micaxistos, quartzo filitos, turmalina quartzitos e metarcósios); Resplandescente (até 300 metros de quartzitos micáceos ou não); Água Preta (com até 30 metros de metaconglomerados, quartzitos, metabrechas e clorita-xistos) e Matão (até 200 metros de quartzitos, quartzitos micáceos e lentes de metaconglomerados).

Para o restante do setor setentrional, a divisão informal utilizada por Roque et al. 1996 (e modificada por Knauer et al. 2006) pode ser aplicada: Unidade Metavulcanossedimentar, com metavulcanitos e metassedimentos associados; Unidade Inferior, com quartzitos de variados tipos e metaconglomerados polimíticos, e Unidade Superior, com quartzitos laminados micáceos, ferruginosos ou não.

A Unidade Metavulcanossedimentar nem sempre aflora, e seu desaparecimento local coincide com o aparecimento de espessos pacotes de quartzitos puros da Unidade Superior, o que pode indicar que a supressão não tem caráter exclusivamente tectônico. Estudada com algum detalhe pelos geólogos do Projeto PorteirinhaMonte Azul (Drumond et al. 1980), a unidade pode ser definida como um conjunto de metavulcanitos ácidos a intermediários com metassedimentos associados, em especial metaconglomerados polimíticos e variados tipos de quartzitos. Menezes-Filho (1980) descreve rochas de tendência riolítica, rochas de tendência andesítica e plutonitos, com um amplo predomínio das primeiras. Os plutonitos gabróicos então descritos são em realidade pertencentes a Suíte Metaígnea Pedro Lessa (Knauer, 1990), de idade Toniana.

Na região de Monte Azul (Knauer et al. 2006), onde a seqüência é mais importante, os metavulcanitos observados caracterizam-se por uma granulação muito fina e coloração cinza-azulada, com pórfiros de quartzo e de feldspato. Além destas rochas, ocorrem vulcanoclásticas metamorfisadas, que apresentam, além de pórfiros de origem vulcânica, clastos arredondados, permitindo a observação de um nítido acamamento composicional

A base da unidade nos locais onde não são observados metavulcanitos, pode ser marcada por extensos e espessos corpos de metaconglomerados polimíticos, tanto matriz- como clasto-suportados. Os clastos são de quartzitos puros, de granitóides e de quartzitos micáceos, além daqueles de quartzo de veio. Nas regiões onde os metaconglomerados localizam-se sobre pacotes metavulcânicos, são comuns fragmentos destas rochas.

Os quartzitos mostram-se desde micáceos e finos até grosseiros a microconglomeráticos e ferruginosos. Estruturas sedimentares típicas são estratificações 


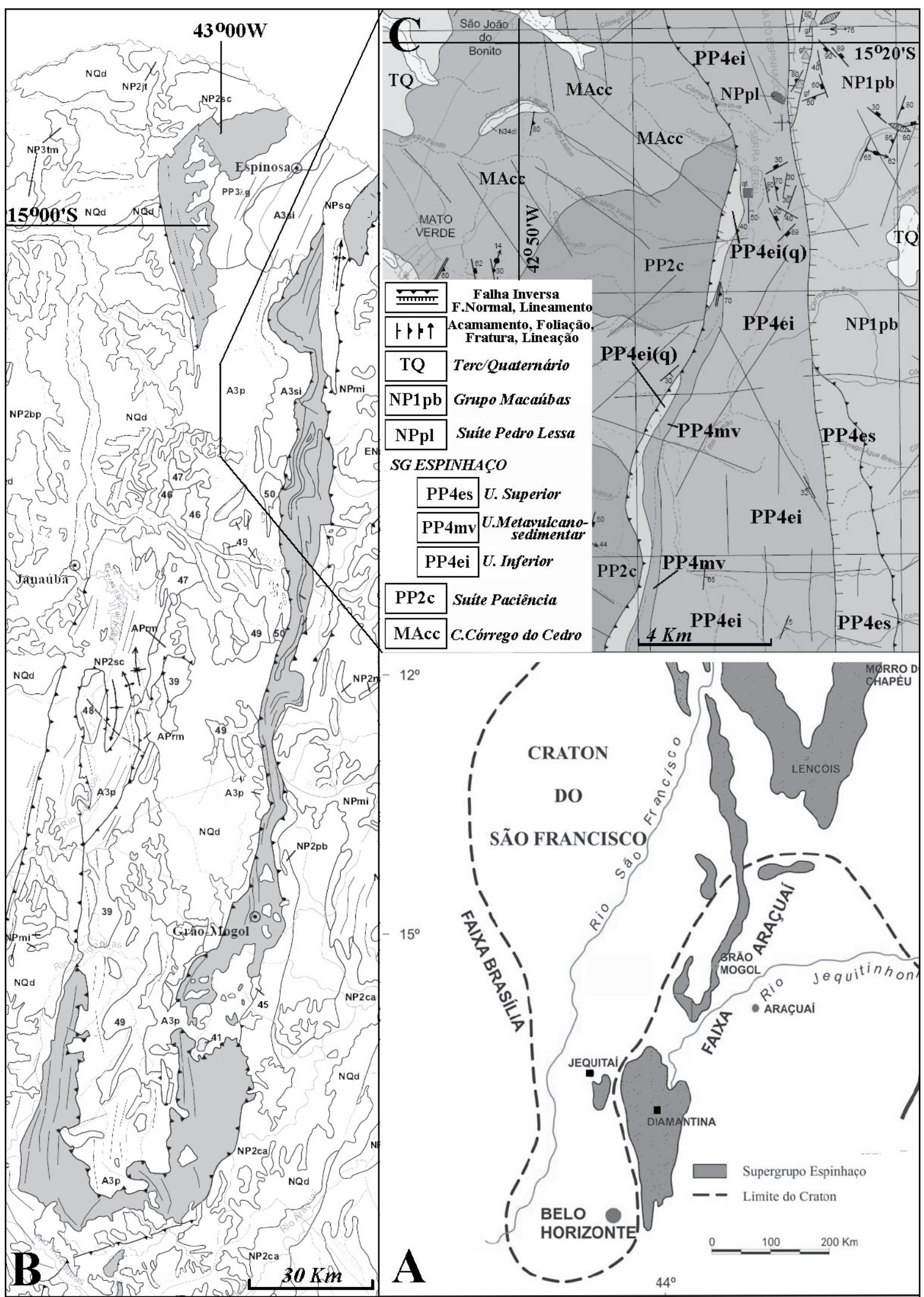

Figura 4 - Mapa com distribuição do Supergrupo Espinhaço (A) no estado (Martins 2006), destacando-se o Setor Setentrional (B, COMIG/CPRM 2003) e seu detalhamento (C) em parte da Folha Monte Azul (Knauer et al. 2006). 
e laminações plano-paralelas e cruzadas tabulares. A presença de marcas onduladas assimétricas e de estratificações cruzadas acanaladas de médio porte pode ser observada com frequência.

A chamada Unidade Inferior é caracterizada por pacotes quartzíticos com intercalações de metaconglomerados e, mais raramente, quartzo-filitos. Discriminam-se localmente faixas com quartzitos puros de coloração clara, de granulometria fina a média, com estratificação cruzada tabular de pequeno a médio porte e marcas onduladas. Uma análise dos termos quartzíticos da unidade (que não deve ultrapassar os 300 metros de espessura) mostra uma marcante heterogeneidade, sem uma clara lei de distribuição dos tipos litológicos. Embora dominada por quartzitos nos setores mais meridionais, a unidade apresenta ainda intercalações de quartzo xistos, moscovita-quartzo xistos e raros muscovita filitos e metaconglomerados matriz-suportados.

Na Folha Grão Mogol, esta unidade exibe intercalações lenticulares de metaconglomerados com clastos arredondados de quartzo, variados tipos de quartzitos e de quartzitos ferruginosos, podendo localmente apresentar-se diamantíferos. Entretanto, para Chaves et al. (1999), a unidade diamantífera seria mais nova que a Formação Resplandescente (considerada pelos autores como correlacionável a Formação Galho do Miguel), e, consequentemente, não pertencente ao conjunto do Grupo Guinda.

A Unidade Superior também é mais importante para sul, sendo constituída por quartzitos laminados, micáceos e finos, localmente podendo apresentar variações no conteúdo em óxidos de ferro e, mais raramente, por verdadeiros quartzitos arcoseanos. Nestes quartzitos micáceos, são observadas as estruturas sedimentares preservadas desta unidade, representadas por estratificação/laminação planoparalela e estratificação cruzada tabular de pequeno a médio porte, além de marcas onduladas assimétricas, com cristas retilíneas e contínuas até sinuosas e interrompidas.

\section{ASPECTOS ESTRUTURAIS DO SUPERGRUPO ESPINHAÇO}

A estruturação da Serra do Espinhaço é creditada a um sistema de falhas inversas ou de empurrão/zonas de cisalhamento dúctil, cujos planos caracterizam-se por direções dominantemente meridianas e mergulhos moderados até altos para os quadrantes leste. Estes planos separam blocos maiores caracterizados por amplas dobras abertas até fechadas, usualmente assimétricas, com eixos próximos a norte-sul. Uma importante inflexão para sudeste dos planos de falhas inversas nas áreas a sul de Diamantina implica numa crescente importância de componentes sinistrais.

A assembléia estrutural nas litologias do Supergrupo Espinhaço é bastante rica e diversificada (e.g. Schöll \& Fogaça 1981; Herrgesell 1984; Kalt 1991). É interessante destacar que uma série de características comuns ou similares marca não só as rochas do Supergrupo Espinhaço como aquelas relacionadas às unidades mais antigas (e mais novas):

-a- Foliação (muitas vezes de origem milonítica) com valores próximos a norte-sul, com mergulhos para os quadrantes leste;

-b- Duas lineações de interseção tem presença constante, sendo uma de direção norte-sul (originada no plano axial de dobras abertas), e que representa clivagem com altos mergulhos, e outra de direções próximas a leste-oeste;

-c- Lineação de estiramento mineral, com direções em torno de $\mathrm{S} 75^{\circ}-85^{\circ} \mathrm{E}$, paralela ao estiramento dos seixos de metaconglomerados; e

-d- Constante assimetria de elementos, incluindo foliação "S/C", sombras de pressão, "boudinage" de veios, "rod's" rotacionados e "mica-fish".

Estes aspectos, analisados em conjunto com a estruturação regional indicam a ocorrência de evento(s) deformacional(ais) marcado(s) por grande(s) transporte(s) de massa aproximadamente de leste para oeste. Os mergulhos das foliações miloníticas mostram o domínio de movimentos próximos à horizontalidade, com a natureza heterogênea da deformação e o caráter não coaxial permitindo a acomodação de grandes quantidades de "strain".

Considerando áreas/afloramentos com menor deformação, uma estrutura planar se destaca nos quartzitos do Supergrupo Espinhaço, tendo sido designada $S^{*}$ (Knauer 1990). Esta é sempre paralela ao plano da estrutura sedimentar onde se ressalta, ou o acamamento, ou os planos de estratificação cruzada. Tais planos de "minerais planares orientados" paralelos ao acamamento foram correlacionados por Uhlein (1984) ao plano axial de minidobras isoclinais deitadas a recumbentes, mas o caráter tectônico destes planos pode ser descaracterizado, e uma origem não tectônica, ligada a processos deposicionais e/ou diagenéticos é aqui assumida. Esta "foliação" paralela ao acamamento nunca afeta (e nem é afetada) pela "foliação" paralela aos planos de estratificação cruzada.

A principal foliação observada, com predomínio de valores próximos a norte-sul, é facilmente reconhecida nas litologias de origem pelítica, mas também observável pelo menos em parte dos quartzitos e metaconglomerados típicos da unidade. Na região de Diamantina, sua direção situa-se normalmente entre $\mathrm{N} 05^{\circ} \mathrm{W}$ e $\mathrm{N} 15^{\circ} \mathrm{E}$, com mergulhos moderados até altos para os quadrantes leste, e que se mostram mais suaves para o sul da serra. Seu aspecto anastomosado em diferentes escalas, o aparecimento local de estruturas do tipo "S/C" e a ocorrência de "boudinage" de foliação em filitos têm sido usados como critérios para a definição de uma origem "sensu lato" milonítica. A forte inflexão para SE no sul da serra se reflete na orientação preferencial de parte destas estruturas.

O terceiro elemento planar $(\mathrm{Sn}+1)$ é representado por uma clivagem (de fratura ou ardosiana), e que localmente evolui para uma verdadeira xistosidade. 


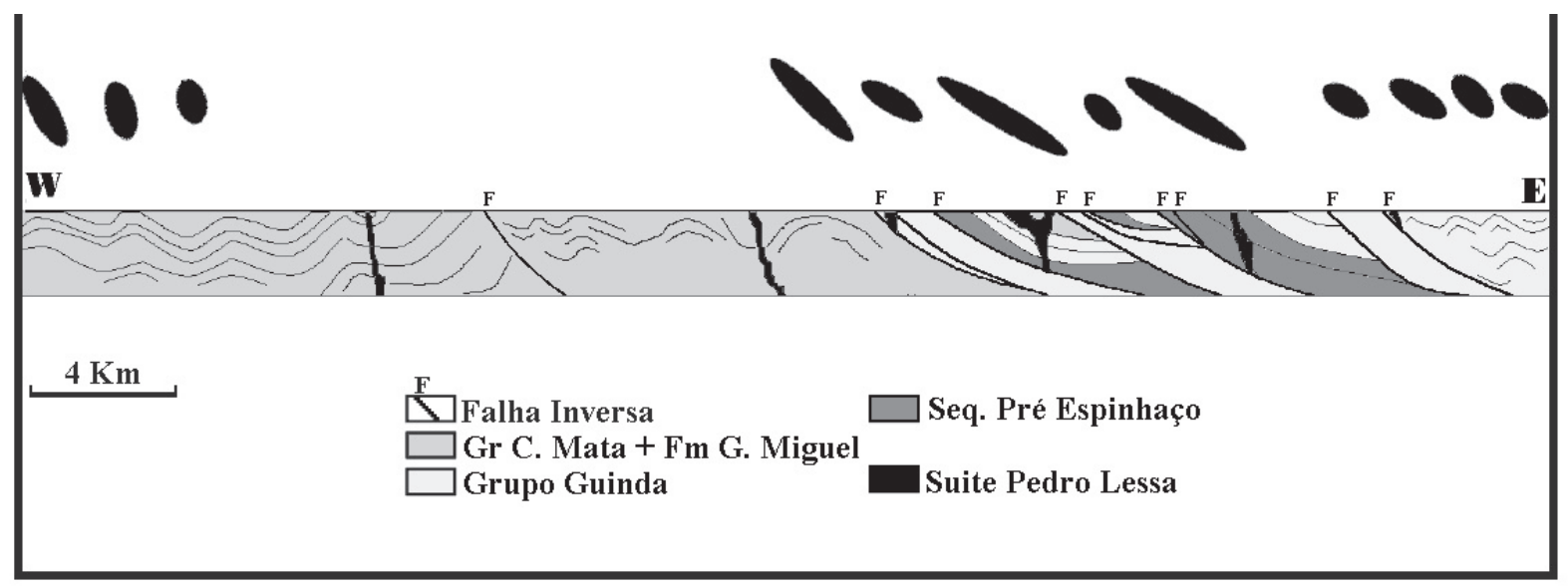

Figura 5 - Perfil Esquemático a sul da cidade de Diamantina, mostrando os elipsóides de deformação determinados em quartzitos do Supergrupo Espinhaço, modificado a partir de Knauer (1999).

Esta foliação está relacionada as grandes dobras abertas (até localmente fechadas) de eixo norte-sul, típicas da maior parte das áreas de afloramento do Supergrupo Espinhaço.

Além das dobras amplas já citadas, é importante ressaltar aquelas centi- a decimétricas de geração "sinmilonítica". Trata-se de dobras fechadas até isoclinais cujos planos axiais mergulham fraca a moderadamente para leste, apresentando direções próximas a nortesul. Com o aumento local do "strain", o progressivo encurvamento de seus eixos pode ser verificado, alcançando valores extremos entre $\mathrm{N} 40^{\circ} \mathrm{W}$ e $\mathrm{N} 50^{\circ} \mathrm{E}$. $\mathrm{Na}$ borda leste da serra, dobras centimétricas com eixos próximos a leste-oeste podem ser os resultantes finais desta reorientação ou mesmo terem se formado diretamente com tal direção, caracterizando dobras "a" em relação ao transporte de massa leste-oeste.

Métodos para a quantificação do "strain" (e.g. Ramsay \& Huber 1983) requerem a presença de "marcadores da deformação", cujas relações de forma, arranjo e posicionamento possibilitam a quantificação das mudanças de um corpo rochoso quando submetido a esforços tectônicos. Usualmente, as análises consideram dois métodos clássicos: o método desenvolvido por Fry (1969) e o “Método Rf/phi”(Ramsay 1967), o primeiro enfatizando a deformação da matriz e o segundo assumindo que os objetos elipsoidais observados são deformados em conjunto (e na mesma proporção) com a matriz que os envolve.

No caso do Supergrupo Espinhaço, o não reconhecimento de fósseis exige a utilização de técnicas de quantificação que considerem apenas características intrínsecas não-paleontológicas das rochas. Assim, afiguram-se viáveis métodos e técnicas passíveis de utilização em atributos provenientes do alto grau de preservação de estruturas sedimentares na unidade, mesmo considerando a influência do "fabric" sedimentar inicial e daquele imposto pela compactação e/ou diagênese no elipsóide final de deformação finita.
Knauer (1999) analisou amostras de rochas quartzíticas incluídas nas principais unidades metassedimentares constituintes da Serra do Espinhaço Meridional, em especial do Supergrupo Espinhaço. Os resultados mostram que os valores de $\mathrm{Ri}$ (razão inicial) obtidos pela aplicação de Rf/phi são altos, variando entre 1,35 e 2,26. Estes valores podem estar refletindo a atuação de evento tectônico anterior, com orientação de esforços basicamente similar aquela do ultimo tectonismo.

Os resultados mostraram que praticamente todas as amostras coletadas nas proximidades de zonas de cisalhamento dúctil/falhas de empurrão apresentam valores de "strain" bastante altos, compatíveis com o contexto geológico anteriormente definido. A realização de um perfil aproximadamente oeste-leste a sul de Diamantina (Figura 5) permite algumas interessantes considerações. Apesar de ser possível uma generalização de aumento da deformação de oeste para leste e para sudeste, os maiores valores determinados de "strain" localizam-se no segmento centro-leste do perfil, reafirmando o caráter heterogêneo da deformação.

\section{CONSIDERAÇÕES FINAIS}

Analisando-se os modelos existentes para a evolução do Supergrupo Espinhaço pode-se generalizar a existência de duas grandes linhas: a) O rift original é abortado, e toda deformação é de idade brasiliana (e.g. Dussin \& Dussin 1995; Uhlein et al. 1995); b) O rift evolui para uma margem passiva, a qual é fechada nos tempos finais do Uruaçuano (e.g. Pflug et al. 1980; Almeida Abreu 1995; Knauer 1990). Para esta ultima, existe a necessidade de que as seqüências aflorantes na região do Serro, incluindo BIF's, quartzitos, filitos e xistos das formações Serra do Sapo e Jacem e os metaultramafitos da Suíte Ultramáfica de Alvorada de Minas (Almeida Abreu e Renger 2002) pertençam ao Supergrupo Espinhaço.

Uma rápida observação mostra que a forte tectônica típica da região impede a verificação de suas reais 
relações estratigráficas com as rochas seguramente pertencentes ao Supergrupo Espinhaço. Quando analisadas sobre o prisma exclusivo do desenvolvimento do Supergrupo Espinhaço, seu posicionamento pósTransamazônico é atraente, até porque seus contatos, mesmo que tectônicos, poderiam marcar variações (continental - marinho raso - plataformal - abissal) compatíveis com uma margem continental passiva.

Por outro lado, os dados geocronológicos existentes até o momento não mostram evidencias de um evento tectônico de idade Uruaçuana na região. Consequentemente, não é possível uma definição segura, mas é provável que modelos mais conservadores para o desenvolvimento do Supergrupo Espinhaço nos tempos Mesoproterozóicos, com evolução abortada antes do desenvolvimento de uma margem passiva devam ser utilizados.

Os metassedimentos das porções inferiores do Grupo Costa Sena (em especial da Formação Barão do Guaicuí) tem deposição bastante posterior à intrusão dos granitos do "Tipo Gouveia" (do qual representam retrabalhamento). Suas características dificultam a atribuição de seu ambiente deposicional, podendose sugerir ambientes continentais a marinhos rasos, inclusive com possível desenvolvimento local de evaporitos (J.J.G. Quemeneur, com.verbal).

As metaígneas ácidas calcialcalinas, com idades $\mathrm{U} / \mathrm{Pb}$ por volta de $2,05 \mathrm{Ga}$. podem representar os produtos dos processos compressivos associados ao Evento Transamazônico. Provavelmente concomitante com estes processos, desenvolve-se um novo sítio deposicional de características continentais, envolvendo em ambientes fluviais até marinhos rasos, com algum retrabalhamento eólico, típicos da Formação Bandeirinha.

Aproveitando linhas de fraqueza herdadas do Evento Transamazônico, a partir dos 1800 milhões de anos inicia-se evento extensional, cuja evolução originará a "Bacia Espinhaço". As unidades representantes deste período inicial na região central da Serra do Espinhaço Meridional mostram características dominantemente continentais, tendo sido normalmente caracterizadas como "fase rift" do desenvolvimento da bacia.

Durante a deposição da Formação São João da Chapada, instalam-se condições que originam extensos derrames basálticos, particularmente na região de Diamantina, onde estiveram em exposição sub-aérea, com desenvolvimento de espessos perfis de alteração, os quais, metamorfisados, darão origem aos filitos hematíticos e as rochas ricas em cloritóide.

A presença de corpos concordantes e discordantes de xistos verdes e de filitos hematíticos é comum também na Formação Sopa-Brumadinho. Com relação a estes corpos discordantes, pode-se afirmar que também estão submetidos a processos de alteração superficial pré-metamórfica. Uma composição original lamproítica ou kimberlítica tem sido proposta para parte destas rochas, consequentemente considerando-as como as fontes originais dos diamantes da região. Deste modo, é algo provável que as duas unidades basais da região central não correspondam efetivamente à deposição em um ambiente de "rift", mas sim a uma estrutura continental sem adelgaçamento importante de crosta.

Uma explicação é a da migração das condições extensionais, com desenvolvimento do "rift" a leste do sítio deposicional descrito. Esta evolução é mostrada por parte da Formação Sopa-Brumadinho e pela Formação Itapanhoacanga, que marcam variações ambientais compatíveis com este modelo. Nas seções basais, e algumas vezes associadas temporalmente à metavulcânicas básicas, podem aparecer metavulcânicas/ subvulcânicas ácidas, mais importantes em Conceição do Mato Dentro, caracterizando magmatismo bimodal, evidência do desenvolvimento do "rift" a leste da região central da serra.

As peculiaridades deste magmatismo podem indicar uma forte fragmentação do rift, que mostra características diferenciadas na direção meridiana e diferentes épocas de evolução. Assim, o magmatismo básico parece ser relativamente raro nos segmentos norte e sul, onde o magmatismo ácido é mais importante. Além disso, pelos dados disponíveis, estas metamagmáticas ácidas apresentam idades caracteristicamente maiores no setor setentrional.

Para oeste, a bacia é recoberta pelos sedimentos eólicos (pelo menos em sua maior parte) da Formação Galho do Miguel. Mais tarde, ainda mais para oeste, provavelmente já em tempos mesoproterozóicos, como resultado de localizada subsidência termal, desenvolve-se bacia interior responsável pela deposição dos sedimentos de águas marinhas calmas do Grupo Conselheiro Mata.

\section{Agradecimentos}

$\mathrm{O}$ autor agradece os alunos das universidades brasileiras que participaram dos estágios do C.G.Eschwege, em especial M.K. Amaral, H.L. Reis, D.G. Fragoso, J.T. Magalhães e D.A. Costa; a Juni Cordeiro, L.L. Silva, D. Piuzana e R.D. Costa pelas discussões e contribuições. Agradece também a A.C. Pedrosa-Soares pelo convite e pela consideração.

\section{REFERÊNCIAS BIBLIOGRÁFICAS}

ALMEIDA ABREU,P.A. 1993. A evolução geodinâmica da Serra do Espinhaço Meridional, Minas Gerais, Brasil . Tese Dout., Univ. Freiburg, 150 pp.

ALMEIDA ABREU,P.A. 1995. O Supergrupo Espinhaço da Serra do Espinhaço Meridional Minas Gerais : o rifte, a bacia e o orógeno. Geonomos 3(1) : 1-18

ALMEIDA ABREU,P.A. \& PFLUG,R. 1994. The geodynamic evolution of the southern Serra do Espinhaço, Minas Gerais, Brazil . Zbl.Geol. Paläont., Teil I, 1994 1/2 : 21-44

ALMEIDA-ABREU, P. A. ; RENGER, F. E. . Serra do Espinhaço Meridional: um orógeno de colisão do Mesoproterozóico. Revista Brasileira de Geociências, São Paulo, v. 32, n. 1, p. 1-14, 2002.

BRITO NEVES,B.B.; SÁ,J.M.; NILSON,A.A. \& BOTELHO,N.F. 1995. A Tafrogênese estateriana nos blocos paleoproterozóicos da América do Sul e processos subsequentes. Geonomos, 3(2) : 1-21, Belo Horizonte.

CHAVES, M. L. S. C. ; KARFUNKEL, J. ; ADDAD, J. 1999. 
Geologia da região diamantífera de Grão Mogol (Minas Gerais). Geociências, Rio Claro, v. 18, n. 1, p. 129-155.

DOSSIN,I.A.; UHLEIN,A. \& DOSSIN,T.M. 1984. Geologia da Faixa Movel Espinhaço em sua porção meridional, MG . XXXIII Cong. Bras. Geol., Anais 7: 3118-3134, Rio de Janeiro.

DOSSIN,I.A.; GARCIA,A.J.V.; UHLEIN,A. \& DOSSIN,T.M. 1987. Facies eólico na Formação Galho do Miguel, Supergrupo Espinhaço-MG. Simp. Sist. Dep. Pré-Cambriano, Anais, pp. 85-96, Ouro Preto.

DRUMOND, J. B., RAPOSO, F. O. e SPERLING, E. von 1980. Projeto Porteirinha - Monte Azul (1:50.000). Relatório Final. Vol.I, DNPM/CPRM, Belo Horizonte, 559 pp.

DUSSIN,I.A. \& DUSSIN,T.M. 1995. Supergrupo Espinhaço: Modelo de evolução geodinâmica. GEONOMOS 3(1): 19-26, B. Horizonte.

FOGAÇA,A.C.C. 1995. Geologia da Folha Diamantina. Projeto Espinhaço, COMIG/UFMG, 98 pp., Belo Horizonte.

FOGAÇA,A.C.C. \& ALMEIDA ABREU,P.A. 1982. Depositos de planicies de mares na Formação Sopa Brumadinho, Proterozoico Inferior da Cordilheira do Espinhaço, Minas Gerais, Brasil. V Cong. Latinoamer. Geol., Actas 2: 373-388, Buenos Aires.

FOGAÇA,A.C.C.; ALMEIDA ABREU,P.A. \& SCHORSCHER,H. D. 1984. Estratigrafia da sequência supracrustal arqueana da porção mediana central da Serra do Espinhaço Meridional, Minas Gerais. XXXIII Cong. Br. Geol., Anais 6: 2654-2667, Rio de Janeiro.

FRY,N. 1979. Random point distributions and strain measurements in rocks. Tectonoph. 60: 89-105.

GROSSI-SAD,J.H. \& MELO,M.F.V. 1969. Geologia do distrito de Serro, Minas Gerais. DNPM/GEOSOL, Rel. Int., $178+110$ pp., Belo Horizonte.

HERRGESELL,G. 1984. Das Prakambriun am Ostrand der nordlichen Serra do Cipó Serra do Espinhaço, Minas Gerais, Brasilien. Un. Freiburg, Tese Dout., 247 pp., Freiburg.

KALT,H. 1991. Untersuchungen zur Schertektonik in der südlichen Serra do Espinhaço und im angrenzenden Teil des São Francisco Beckens, Minas Gerais, Brazilien. Un. Freiburg, Tese Dout., 118p. Freiburg.

KARFUNKEL,B. \& KARFUNKEL,J. 1975. Fazielle entwicklung der mittleren Espinhaço Zone mit besonderer besucksichtigung des tillit problems . Un. Freiburg, Tese Dout., 86 pp. Freiburg.

KNAUER,L.G. 1990. Evolução geológica do Precambriano da porção centro leste da Serra do Espinhaço Meridional e metalogênese associada. Dissertação de Mestrado, UNICAMP, 298p. Campinas.

KNAUER, L. G. 1999. Serra do Espinhaço Meridional : Considerações sobre a estratigrafia e a análise da deformação das unidades proterozóicas. Tese de Doutorado,UNESP, 244, Rio Claro.

KNAUER,L.G. \& SCHRANK,A. 1994. A origem dos filitos hematíticos da Serra do Espinhaço Meridional, Minas Gerais, GEONOMOS, 1(1): 33-38. Belo Horizonte.

KNAUER, L. G.; GROSSI-SAD, J. H. 1996. Geologia da Folha Serro (SE-23-Z-B-IV). In: GROSSI SAD, J. H.; LOBATO, L. M.; PEDROSA-SOARES, A. C. et al. (Eds.) Projeto Espinhaço. Belo Horizonte: COMIG, 1997. 1 CD-ROM.

KNAUER, L. G.; GROSSI-SAD. J. H. 1996a. Geologia da Folha Presidente Kubitschek (SE-23-Z-A-VI). In: GROSSI SAD, J. H.; LOBATO, L. M.; PEDROSA-SOARES, A. C. et al. (Eds.) Projeto Espinhaço. Belo Horizonte: COMIG, 1997. 1 CD-ROM.

KNAUER,L.G. \& EBERT,H.D. 1997. Estruturação tectônica da região de Diamantina, $\mathrm{MG}$ e considerações sobre a idade do Orógeno Espinhaço. VI Simp. Nac. Est. Tectônicos, Anais, 56-58.
KNAUER, L.G.; SILVA, L.L.; SOUZA, F.B.; SILVA, L.R. \& CARMO, R.B. (2006). Folha Monte Azul 1:100.000 - Relatório Final. Convenio UFMG/CPRM, Programa Geologia do Brasil, 87 pp., Brasília.

MACHADO,N.; SCHRANK,A.; ABREU,F.R.; KNAUER,L.G. \& ALMEIDA ABREU,P.A. 1989. Resultados preliminares da geocronologia $\mathrm{U} / \mathrm{Pb}$ na Serra do Espinhaço Meridional. V Simp. Geol. Minas Gerais, Anais, pp. 171-174, Belo Horizonte.

MARTINS, M.S. 2006 Geologia dos diamantes e carbonados aluvionares da bacia do rio Macaúbas (MG). Tese de doutorado, IGC-UFMG, 210, Belo Horizonte.

MARTINS NETO,M.A. 1993. The sedimentary evolution of a Proterozoic rift basin: the basal Espinhaço Supergroup, southern Serra do Espinhaço, Minas Gerais, Brazil. Freiburger geowiss Beitr., Bd. 4, 155p.

MARTINS-NETO, M.A. 1998. O Supergrupo Espinhaço em Minas Gerais: registro de uma bacia rift-sag do Paleo/Mesoproterozóico. Rev. Bras. Geoc., 28(2):151-168.

MENEZES-FILHO, N.R. 1980. Seqüência vulcano/vulcanoclástica da Serra do Riacho Seco (Monte Azul, MG) - Supergrupo Espinhaço. In: XXXI Cong. Bras. Geol.,Camboriú, vol.4, p. 2104-2118.

MOURÃO,M.A.A. 1995. A unidade fosfática da Formação Sopa Brumadinho, Supergrupo Espinhaço Região de Conceição do Mato Dentro, Minas Gerais. Dissertação de Mestrado, UNB, 138p. Brasília.

PEDROSA-SOARES,A.C.; NOCE,C.M.; VIDAL.P.; MONTEIRO,R. \& LEONARDOS,O.H. 1992. Towards a new tectonic model for the Late Proterozoic Araçuaí (SE Brazil) - West Congolian (SW Africa) belt. J. S. Am. Earth Sc., 6: 33-47.

PFLUG,R. 1968. Observações sobre a estratigrafia da Série Minas na região de Diamantina, Minas Gerais . DNPM/DGM, Not. Prel. Est. 142: 1-20, Rio de Janeiro.

PFLUG,R.; HOPPE,A. \& BRICHTA,A. 1980. Paleogeografia do Pré Cambriano na Serra do Espinhaço, Minas Gerais, Brasil. III Geow. Lat. Koll., Anais , pp. 33-40, Boppard.

RAMSAY,J.G. 1967. Folding and fracturing rocks. McGraw Hill Book Co., 327 pp, N. York.

RAMSAY,J.G. \& HUBER,M.I. 1983. The techniques of modern structural geology: strain analysis. Acad. Press, 278 pp, N York.

RENGER,F. 1979. Evolução dos conceitos geológicos da Serra do Espinhaço. I Simp. Geol. Minas Gerais, Anais, pp. 9-27, Diamantina.

RENGER,F.E. \& KNAUER,L.G. 1995. Espinhaço: Quo vadis? onde está? Aonde vai? A evolução dos conhecimentos sobre a Cordilheira do Espinhaço Meridional em Minas Gerais entre 1979 e 1995. GEONOMOS, 3(1). 31-39.

ROQUE,N.C.; GUIMARÃES,M.L.V.; NOCE,C.M.; KNAUER,L. G. \& GROSSI SAD,J.H. 1996.Mapa geológico 1:100.000 da Folha Rio Pardo de Minas, Minas Gerais. Projeto Espinhaço, Convênio COMIG/UFMG.

SCHOLL,W.U. \& FOGAÇA,A.C.C. 1979. Estratigrafia da Serra do Espinhaço na região de Diamantina. I Simp. Geol. Minas Gerais, Anais, pp. 55-73, Diamantina.

SILVA,R.R. 1995. Sequence stratigraphy and depositional systems of the lower Espinhaço in the region between Diamantina and Gouveia, Minas Gerais, Brazil. Tese de Doutoramento, Univ. Freiburg, Alemanha.

UHLEIN,A. 1982. Geologia e mineralogia da cromita e itabiritos da região do Serro MG. UnB, Tese Mest., 192 pp., Brasilia.

UHLEIN,A. 1984. Análise estrutural nas formações inferiores do Supergrupo Espinhaço na região de Datas, Minas Gerais. XXXIII Cong. Bras. Geol., Anais 6: 3381-3392, Rio de Janeiro.

UHLEIN,A. 1991. Transição cráton faixa dobrada: exemplo do Craton São Francisco e da Faixa Araçuai-Ciclo Brasiliano no Estado de Minas Gerais. Aspectos estratigráficos e estruturais. Tese de Doutoramento, USP. 295p. São Paulo. 